\title{
Emmanuel Buron, Le réemploi dans les «Escriz de divers poëtes à la louenge de Louize Labé» (Baïf, Tyard et Scève)
}

\section{Filippo Fonio}

\section{(2) OpenEdition \\ Journals}

Edizione digitale

URL: http://journals.openedition.org/studifrancesi/27402

DOI: $10.4000 /$ studifrancesi.27402

ISSN: 2421-5856

\section{Editore}

Rosenberg \& Sellier

\section{Edizione cartacea}

Data di pubblicazione: 31 décembre 2006

Paginazione: 591

ISSN: 0039-2944

\section{Notizia bibliografica digitale}

Filippo Fonio, «Emmanuel Buron, Le réemploi dans les «Escriz de divers poëtes à la louenge de Louize Labé» (Baiif, Tyard et Scève) », Studi Francesi [Online], 150 (L | III) | 2006, online dal 30 novembre 2015, consultato il 08 novembre 2020. URL : http://journals.openedition.org/studifrancesi/27402 ; DOI : https://doi.org/10.4000/studifrancesi.27402

\section{Questo documento è stato generato automaticamente il 8 novembre 2020}

\section{cc) $(9)$}

Studi Francesi è distribuita con Licenza Creative Commons Attribuzione - Non commerciale - Non opere derivate 4.0 Internazionale. 
Emmanuel Buron, Le réemploi dans les «Escriz de divers poëtes à la louenge de Louize Labé» (Baïf, Tyard et Scève)

Filippo Fonio 


\section{NOTIZIA}

EMMANUEL BURON, Le réemploi dans les «Escriz de divers poëtes à la louenge de Louize Labé» (Baï, Tyard et Scève), «Bibliothèque d'Humanisme et Renaissance», LXVII, 3 (2005), pp. 575-596.

Gli Escriz de divers poëtes à la louenge de Louize Labé Lionnoize, collocati in appendice alle Euvres della poetessa (Lyon, Jean de Tournes, 1555), constano di ventiquattro componimenti, per lo più anonimi. Si tratta di un primo tentativo di costruzione della biografia intellettuale della poetessa, dal quale traspare l'immagine di una cortigiana ben integrata nei cenacoli lionesi e ammirata tanto per la bellezza quanto per l'opera. Lo studioso fa emergere piuttosto il carattere di operazione editoriale degli Escriz, pensati 'a tavolino' come complemento encomiastico del canzoniere della Labé, e caratterizzati, presumibilmente nella quasi totalità dei casi, dal reimpiego di liriche all'insaputa dei poeti. Buron si sofferma sulle liriche di Baï, Tyard e Scève, reimpiegate per l'occasione adattandole al contesto, osservando come la maggior parte dei testi inseriti negli Escriz contengano solo nel titolo riferimenti alla Labé, cosa che non attesta di per sé che essi siano stati scritti per la poetessa lionese, essendo piuttosto frequente il caso che queste nugae venissero riutilizzare attraverso un cambiamento del dedicatario e aggiustamenti di scarso rilievo. Il modello per gli Escriz va identificato nell'edizione delle Rime di Tullia d'Aragona (Venezia, Gioito, 1547), anch'esse suddivise in 'liriche di...' e 'liriche per...', parallelo efficace a maggior ragione date le analogie biografiche e artistiche fra le due figure. 